\title{
PERBAIKAN KUALITAS PROSES PRODUKSI DENGAN PENDEKATAN LEAN-SIGMA DI PT. AUTOKORINDO PRATAMA, GRESIK
}

\author{
Ni Luh Putu Hariastuti ${ }^{1}$, Rony Nurcahya ${ }^{2}$ \\ Jurusan Teknik Industri, Fakultas Teknologi Industri, \\ Institut Teknologi Adhi Tama Surabaya, Jl. Arief Rachman Hakim 100 Surabaya \\ Email:putu_hrs@yahoo.com; rony02733@gmail.com
}

\begin{abstract}
PT. Autokorindo Pratama Gresik is as one wheel truck and bus manufacturer in Indonesia. This study focuses on the incorporation of the concept of the concept of lean manufacturing and lean sigma to improve quality. Lean sigma tools used in this study is Value Stream Mapping, Pareto charts, fishbone diagrams, and Failure Mode and Effect Analysis. The results were obtained waste most critical that is waste of defects, waste motion, and transportation and waste production processes waiting on disc, rim, ring, assy, and paint. In this study the highest defect types of waste are not part corresponding dimensions on expanding the production process contained in the rim with the number of defects 1900 units and waste transportation is the distance between the assy with the paint as far as $100 \mathrm{~m}$. With these improvements are expected to resolve the problems associated with the defect minimizing waste, waiting, motion, and transportation.
\end{abstract}

Keywords: Waste, Lean Sigma, Value Stream Mapping, Pareto Chart, Fishbone Diagram, and Failure Mode and Effect Analysis.

\begin{abstract}
ABSTRAK
PT. Autokorindo Pratama Gresik adalah sebagai salah satu produsen velg truck dan bus di Indonesia. Penelitian ini menitik beratkan pada penggabungan konsep lean manufactur dan konsep six sigma yaitu lean sigma untuk memperbaiki kualitas. Tools lean sigma yang dipakai pada penelitian ini adalah Value Stream Mapping, pareto chart, fishbone diagram, dan Failure Mode and Effect Analysis. Dari hasil penelitian diperoleh waste terkritis yaitu waste defect, waste motion, dan transportation dan waste waiting pada proses produksi disc, rim, ring, assy, dan paint. Dalam penelitian ini jenis waste defect tertinggi adalah dimensi part tidak sesuai pada proses expanding yang terdapat pada proses produksi rim dengan jumlah defect 1900 unit. Dan waste transportation adalah jarak antara proses assy dengan proses paint sejauh $100 \mathrm{~m}$. Dengan perbaikan ini diharapkan dapat menyelesaikan masalah yang berkaitan dengan meminimalisasi terjadinya waste defect, waiting, motion, dan transportation.
\end{abstract}

Kata Kunci: Waste, Lean Sigma,Value Stream Mapping, Pareto Chart, Fishbone Diagram, dan Failure Mode and Effect Analysis.

\section{PENDAHULUAN}

Pengendalian kualitas merupakan salah satu kegiatan yang sangat erat kaitannya dengan proses produksi. Dimana pada pengendalian kualitas dilakukan pemeriksaan serta pengujian karakteristik kualitas yang dimiliki oleh produk untuk proses penilaian atas kemampuan proses produksinya yang dikaitkan dengan standar spesifikasi produk. Analisis lebih lanjut atas hasil pengujian serta pemeriksaan yang dilakukan akan diperoleh sebab sebab terjadinya penyimpangan untuk kemudian diambil langkah-langkah pencegahan dan perbaikan. Perbaikan kualitas merupakan tindakan untuk mengurangi defect produk serta pemborosan proses yang terjadi didalam proses produksi, dimana dua hal ini dapat mempengaruhi kualitas dari produk tersebut.

Lean-Sigma merupakan kombinasi antara konsep Lean dan konsep Six Sigma. Lean-Sigma pada dasarnya sangat baik diterapkan karena dengan six sigma perusahaan dapat mengurangi kecacatan atau variasi cacat sedangkan dengan lean perusahaan dapat memisahkan aktivitas yang bernilai tambah (value added activities) dan aktivitas yang tidak mempunyai nilai tambah (non value added activities) sehingga dapat meningkatkan kecepatan proses produksi [1]. Penelitian mengenai kualitas produk dengan pendekatan lean-sigma telah dilakukan oleh beberapa peneliti 
sebelumnya. Dari hasil penelitian menunjukkan bahwa defect dan waste berupa non value added activity pada aktivitas produksi khsususnya pada waktu tunggu menjadikan proses produksi tidak efektif) [2]. Selain itu penelitian dengan metode lean six sigma berdasarkan nilai COPQ yang dilakukan disebuah bank bertujuan untuk mengurangi waktu antrian nasabah) [3]. Integrasi model lean-sigma untuk peningkatan kualitas produk dapat dilakukan untuk mengurangi produk cacat yang dihasilkan dalam proses produksi [4]. Berdasarkan beberapa penelitian yang telah dilakukan tersebut, belum ada sebuah penelitian yang melakukan pengamatan dan perbaikan kualitas pada objek Manufaktur otomotif khususnya pada produk velg. Maka untuk menyelesaikan permasalahan yang terjadi pada proses produksi produk velg, kegiatan penelitian ini dilakukan

PT. Autokorindo Pratama Gresik sebagai salah satu produsen velg di Indonesia sedang menghadapi permasalahan dalam hal kualitas produknya. PT. Autokorindo Pratama berada dijalan Mayjen Sungkono XVI, Kebomas, Gresik. Berbagai macam tipe velg yang diproduksi oleh PT. Autokorindo Pratama Gresik seperti velg tipe $6.00 \mathrm{H} 150$ x 16, $6.00 \mathrm{H} 164$ x 16, 7.50V x 20, dan 5.50F x 16. Selama ini perusahaan tidak jarang melalui proses produksi dengan tingkat cacat (defect) dan pemborosan (waste) yang cukup tinggi khususnya pada produksi velg tipe $6.00 \mathrm{H} 164 \mathrm{x}$ 16. Jenis cacat yang terjadi, misalnya ketidaksesuaian dimensi, dan retak dengan persentase berkisar antara $1,93 \%$ per total produksi, dimana standart yang ditetapkan oleh perusahaan terhadap tingkat cacat yaitu sebesar $1 \%$. Tipe velg ini adalah tipe velg yang banyak diminta oleh konsumen, maka dari itu tipe velg inilah yang dalam proses produksinya memiliki tingkat cacat (defect) dan pemborosan (waste) yang cukup tinggi. Lean-sigma merupakan salah satu metodologi dan konsep berpikir didalam dunia manufaktur untuk mengurangi kecacatan dan mengeliminasi pemborosan (waste) sehingga dapat meningkatkan kualitas proses produksi [5]. Karena dalam proses produksi velg tipe $6.00 \mathrm{H} 164 \times 16$ memiliki tingkat cacat (defect) dan pemborosan (waste) yang cukup tinggi maka dengan menggunakan pendekatan lean-sigma dalam penelitian ini diharapkan nantinya akan didapatkan rekomendasi perbaikan kualitas proses produksi dan menurunkan tingkat cacat yang terjadi pada produksi velg tipe $6.00 \mathrm{H} 164 \times 16$ ini.

\section{TINJAUAN PUSTAKA}

\section{Pengertian Kualitas}

Pembahasan tentang kualitas melibatkan permasalahan bagaimana mendefinisikan, bagaimana mengukur, dan bagaimana menghubungkannya dengan laba. Banyak pakar dibidang kualitas yang mencoba untuk mendefinisikan kualitas berdasarkan sudut pandangnya masingmasing, seperti tiga pakar kualitas tingkat internasional, yaitu mengacu pada pendapat W.Edwards Deming, Philip B. Crosby dan Joseph M.Juran, dalam Zulian Yamit, (2001). Deming mendefinisikan kualitas adalah apapun yang menjadi kebutuhan dan keinginan konsumen. Crosby mempersepsikan kualitas sebagai nihil cacat, kesempurnaan dan kesesuaian terhadap persyaratan. Juran mendefinisikan kualitas sebagai kesesuaian terhadap spesifikasi, jika dilihat dari sudut pandang produsen.[6].

\section{Sistem Produksi Lean}

Sistem produksi Lean atau yang lebih dikenal sebagai Lean adalah suatu upaya terusmenerus untuk menghilangkan pemborosan (waste) dan meningkatkan nilai tambah (value added) produk (barang/jasa) agar memberikan nilai kepada pelanggan (customer value). [7]

\section{Risk Priority Number (RPN)}

RPN merupakan kriteria evaluasi dalam FMEA proses yang sesuai dengan standart AIAG (Automotive Industri Action Group) [8], merupakan perkalian dari rating occurrence (O), severity (S) dan detection (D). Angka ini digunakan sebagai panduan untuk mengetahui masalah yang paling serius, dengan indikasi angka yang paling tinggi memerlukan prioritas penanganan serius. 


\section{METODE}

Penelitian dengan menerapkan lean-sigma terdiri atas beberapa tahapan DMAIC, yaitu Define, Measure, Analysis, Improve, dan Control Tahap lean-sigma yang pertama adalah define, yakni mendefinisikan aliran informasi dan aliran material pada proses produksi velg tipe $6.00 \mathrm{H} 164$ x 16 dalam tiap - tiap prosesnya dengan menggunakan value stream mapping. Selanjutnya berdasarkan atas mapping yang dilakukan dapat ditentukan critical to quality (CTQ) / karakteristik kualitas pada proses produksi velg tipe $6.00 \mathrm{H} 164$ x 16 dalam tiap - tiap prosesnya. Pada tahap measure hal yang dilakukan adalah mengidentifikasi waste (non-value added activity) yang paling berpengaruh pada proses produksi velg tipe $6.00 \mathrm{H} 164$ x 16 dalam tiap - tiap prosesnya, serta pengukuran baseline kinerja pada proses produksi velg tipe $6.00 \mathrm{H} 164$ x 16 dalam tiap - tiap prosesnya Tahap analyze hal yang dilakukan adalah menganalisis faktor - faktor penyebab terjadinya waste dan defect pada proses produksi velg tipe $6.00 \mathrm{H} 164 \times 16$ dalam tiap - tiap prosesnya. Tools yang dapat digunakan yaitu diagram pareto, diagram ishikawa Tahap improve hal yang dilakukan adalah menentukan urutan prioritas perbaikan berdasarkan nilai RPN (risk priority number) yang menjadi penyebab terjadinya defect pada produksi velg tipe $6.00 \mathrm{H} 164 \times 16$ dalam tiap - tiap prosesnya dan menentukan usulan perbaikan yang menjadi penyebab terjadinya waste Tahap control merupakan tahap operasional terakhir dari metode DMAIC, dimana tahap ini akan dibuat rekomendasi perbaikan sehingga setiap proses dalam produksi velg tipe $6.00 \mathrm{H} 164 \times 16$ dapat dikendalikan dan diharapkan kinerja tidak menurun serta waste dan cacat yang terjadi dapat diminimasi

\section{HASIL DAN PEMBAHASAN}

\section{Tahap Define}

Mendefinisikan aliran informasi dan aliran material pada proses ring, disc, rim, assy, dan paint dengan menggunakan value stream mapping, menentukan karakteristik kualitas dan menentukan karakteristik kritis terhadap kualitas kunci CTQ (Critical to Quality) pada proses ring, disc, rim, assy, dan paint. Hasil evaluasi value stream mapping dan karakteristik kritis terhadap kualitas kunci CTQ (Critical to Quality) pada proses produksi rim, dapat dinyatakan dalam tabel berikut

Tabel 1. CTQ proses produksi rim

\begin{tabular}{|c|c|c|c|c|}
\hline \multirow{2}{*}{ Proses } & \multicolumn{2}{|c|}{ Karakteristik Kualitas } & \multicolumn{2}{|c|}{ Kriteria Cacat } \\
\hline & Atribut & Variabel & Atribut & Variabel \\
\hline Coiler & $\begin{array}{l}\text { Circum df : } 1408 \\
\pm 4,0 \mathrm{~mm} \\
\text { Circum d1 : } 1255 \\
\pm 4,0 \mathrm{~mm} \\
\text { Circum d2 : } 1303 \\
\pm 4,0 \mathrm{~mm} \\
\text { Circum dg : } 1309 \\
\pm 4,0 \mathrm{~mm}\end{array}$ & & $\begin{array}{l}\text { Circum df tidak sesuai : } \\
1408 \pm 4,0 \mathrm{~mm} \\
\text { Circum } \mathrm{d} 1 \text { tidak sesuai } \\
: 1255 \pm 4,0 \mathrm{~mm} \\
\text { Circum d2 tidak sesuai } \\
: 1303 \pm 4,0 \mathrm{~mm} \\
\text { Circum dg tidak sesuai } \\
: 1309 \pm 4,0 \mathrm{~mm}\end{array}$ & \\
\hline $\begin{array}{l}\text { Flatening \& } \\
\text { Marking }\end{array}$ & $\begin{array}{l}\text { Flatening } \\
\text { Jarak rim in dan } \\
\text { out : } 1 \mathrm{~mm} \\
\text { Jarak spiral : } 3 \\
\text { mm }\end{array}$ & $\begin{array}{l}\text { Marking } \\
\text { Type sesuai, } \\
\text { dan lot no } \\
\text { sesuai }\end{array}$ & $\begin{array}{l}\text { Flatening } \\
\text { Jarak rim in dan out } \\
\text { tidak sesuai : } 1 \mathrm{~mm} \\
\text { Jarak spiral tidak sesuai } \\
: 3 \mathrm{~mm}\end{array}$ & $\begin{array}{l}\text { Marking } \\
\text { Type tidak sesuai, } \\
\text { dan lot no tidak } \\
\text { sesuai }\end{array}$ \\
\hline $\begin{array}{l}\text { Flash Butt } \\
\text { Welding }\end{array}$ & & $\begin{array}{l}\text { Hasil } \\
\text { pengelasan } \\
\text { bagus, dan } \\
\text { tidak retak }\end{array}$ & & $\begin{array}{l}\text { Hasil pengelasan } \\
\text { tidak bagus, dan retak }\end{array}$ \\
\hline Trimming & & Tidak retak & & Retak \\
\hline $\begin{array}{l}\text { Side cut \& } \\
\text { Round }\end{array}$ & & Tidak retak & & Retak \\
\hline Grinding & & Rata / halus & & Tidak rata/tidak halus \\
\hline
\end{tabular}




\begin{tabular}{|c|c|c|c|c|}
\hline \multirow{2}{*}{ Proses } & \multicolumn{2}{|c|}{ Karakteristik Kualitas } & \multicolumn{2}{|c|}{ Kriteria Cacat } \\
\hline & Atribut & Variabel & Atribut & Variabel \\
\hline Expanding & $\begin{array}{l}\text { Circum df : } 1450 \\
\pm 2,0 \mathrm{~mm} \\
\text { Circum d1 : } 1277 \\
\pm 2,0 \mathrm{~mm} \\
\text { Circum d2 : } 1284 \\
\pm 4,0 \mathrm{~mm} \\
\text { Circum dg : } 1289 \\
\pm 4,0 \mathrm{~mm}\end{array}$ & & $\begin{array}{l}\text { Circum df tidak sesuai : } \\
1450 \pm 2,0 \mathrm{~mm} \\
\text { Circum } \mathrm{d} 1 \text { tidak sesuai } \\
: 1277 \pm 2,0 \mathrm{~mm} \\
\text { Circum } \mathrm{d} 2 \text { tidak sesuai: } \\
1284 \pm 4,0 \mathrm{~mm} \\
\text { Circum } \mathrm{dg} \text { tidak sesuai } \\
: 1289 \pm 4,0 \mathrm{~mm}\end{array}$ & Expanding \\
\hline Shrinking & $\begin{array}{l}\text { Circum df : } 1449 \\
\pm 2,0 \mathrm{~mm} \\
\text { Circum d1: } \\
1269,8 \pm 1,2 \mathrm{~mm} \\
\text { Circum d2: } 1259 \\
\pm 1,0 \mathrm{~mm} \\
\text { Circum dg : } 1247 \\
\pm 0,5 \mathrm{~mm}\end{array}$ & & $\begin{array}{l}\text { Circum df tidak sesuai : } \\
1449 \pm 2,0 \mathrm{~mm} \\
\text { Circum } \mathrm{d} 1 \text { tidak sesuai : } \\
1269,8 \pm 1,2 \mathrm{~mm} \\
\text { Circum } \mathrm{d} 2 \text { tidak sesuai : } \\
1259 \pm 1,0 \mathrm{~mm} \\
\text { Circum } \mathrm{dg} \text { tidak sesuai : } \\
1247 \pm 0,5 \mathrm{~mm}\end{array}$ & Shrinking \\
\hline $\begin{array}{c}\text { Valve / hole } \\
\text { pierching }\end{array}$ & $\begin{array}{l}\text { Jarak valve : } 40 \pm \\
1,0 \mathrm{~mm} \\
\text { Lebar valve : } 14- \\
16 \mathrm{~mm} \\
\text { Panjang valve : } \\
50 \pm 0,8 \mathrm{~mm} \\
\text { Tinggi flange: } \\
17 \pm 3 \mathrm{~mm} \\
\text { Lebar rim : } 153 \pm \\
2 \mathrm{~mm} \\
\text { Tebal gutter }: 15 \\
\pm 0,3 \mathrm{~mm}\end{array}$ & & $\begin{array}{l}\text { Jarak valve tidak sesuai } \\
: 40 \pm 1,0 \mathrm{~mm} \\
\text { Lebar valve tidak sesuai } \\
: 14-16 \mathrm{~mm} \\
\text { Panjang valve tidak } \\
\text { sesuai : } 50 \pm 0,8 \mathrm{~mm} \\
\text { Tinggi flange tidak } \\
\text { sesuai : } 17 \pm 3 \mathrm{~mm} \\
\text { Lebar rim tidak sesuai : } \\
153 \pm 2 \mathrm{~mm} \\
\text { Tebal gutter tidak } \\
\text { sesuai : } 15 \pm 0,3 \mathrm{~mm}\end{array}$ & $\begin{array}{c}\text { Valve / hole } \\
\text { pierching }\end{array}$ \\
\hline
\end{tabular}

\section{Tahap Measure}

Mengidentifikasi waste (non- value added activity) yang paling berpengaruh pada proses ring, disc, rim, assy, dan paint, serta pengukuran baseline kinerja pada proses ring, disc, rim, assy, dan paint. Adapun hasil identifikasi waste dinyatakan dalam tabel2.

Tabel 2. Hasil Penilaian Rating Pada Proses Produksi Rim

\begin{tabular}{|c|c|c|c|c|c|c|c|}
\hline \multirow{2}{*}{ No } & \multirow{2}{*}{ Waste } & \multicolumn{5}{|c|}{ Responden ke } & \multirow{2}{*}{ Rata - Rata } \\
\cline { 3 - 7 } & & $\mathbf{1}$ & $\mathbf{2}$ & $\mathbf{3}$ & $\mathbf{4}$ & $\mathbf{5}$ & \\
\hline 1. & Defect & 5 & 5 & 5 & 5 & 4 & 4,8 \\
\hline 2. & Over Production & 2 & 2 & 3 & 2 & 3 & 2,4 \\
\hline 3. & Waiting & 4 & 5 & 5 & 4 & 5 & 4,6 \\
\hline 4. & Transportation & 2 & 3 & 3 & 3 & 3 & 2,8 \\
\hline 5. & Inventories & 2 & 2 & 2 & 2 & 3 & 2,2 \\
\hline 6. & Motion & 4 & 5 & 5 & 4 & 4 & 4,4 \\
\hline 7. & Over process & 2 & 2 & 3 & 3 & 3 & 2,6 \\
\hline
\end{tabular}

Tabel 3. Kapabilitas Sigma dan DPMO tiap proses

\begin{tabular}{|c|c|c|c|c|c|}
\hline Proses & $\begin{array}{c}\text { Jumlah Produk } \\
\text { Yang Diperiksa } \\
\text { (unit) }\end{array}$ & $\begin{array}{c}\text { Jumlah } \\
\text { Defect } \\
\text { (unit) }\end{array}$ & $\begin{array}{c}\text { Jumlah } \\
\text { CTQ } \\
\text { Potensial }\end{array}$ & DPMO & Sigma \\
\hline Disc & 135.385 & 292 & 5 & 431 & 4,85 \\
\hline Rim & 138.123 & 2083 & 6 & 25.100 & 3,46 \\
\hline Ring & 141.335 & 250 & 5 & 353 & 4,91 \\
\hline Assy & 136.135 & 4 & 2 & 14 & 5,7 \\
\hline Total & 550.978 & 2629 & 5 & 954 & 4,6 \\
\hline
\end{tabular}




\section{Tahap Analyze}

Pada tahap analyze hal yang dilakukan adalah menganalisis faktor - faktor penyebab terjadinya waste dan defect pada proses produksi velg tipe $6.00 \mathrm{H} 164$ x 16 dalam tiap - tiap prosesnya .

Tabel 4. Jumlah jenis defect proses produksi velg tipe $6.00 \mathrm{~h} 164$ x 16

\begin{tabular}{|c|c|c|c|c|}
\hline No. & Jenis Defect & $\begin{array}{l}\text { Jumlah } \\
\text { Defect }\end{array}$ & $\begin{array}{l}\text { Prosentase } \\
(\%)\end{array}$ & $\begin{array}{l}\text { Kumulatif } \\
\text { Prosentase } \\
(\%)\end{array}$ \\
\hline 1. & $\begin{array}{l}\text { Dimensi part tidak sesuai pada proses } \\
\text { expanding }\end{array}$ & 1900 & 72,2 & 72,2 \\
\hline 2. & $\begin{array}{l}\text { Dimensi kedua sisi part tidak sama pada } \\
\text { proses blanking }\end{array}$ & 100 & 3,8 & 76 \\
\hline 3. & $\begin{array}{l}\text { Hasil pengelasan part tidak bagus dan retak } \\
\text { pada proses welding }\end{array}$ & 80 & 3,0 & 79 \\
\hline 4. & $\begin{array}{l}\text { Diameter dan radius part tidak sesuai pada } \\
\text { proses chamfer } 1\end{array}$ & 80 & 3,0 & 82 \\
\hline 5. & $\begin{array}{l}\text { Dimensi part tidak sesuai pada proses } \\
\text { coiler }\end{array}$ & 80 & 3,0 & 85 \\
\hline 6. & $\begin{array}{l}\text { Circum gutter tidak sesuai pada proses } \\
\text { shrinking }\end{array}$ & 80 & 3,0 & 88 \\
\hline 7. & $\begin{array}{l}\text { Dimensi part tidak sesuai pada proses } \\
\text { coiler }\end{array}$ & 43 & 1,6 & 89,6 \\
\hline 8. & $\begin{array}{l}\text { Dimensi part tidak sesuai dan adanya tajam } \\
\text { pada proses bolt/hole }\end{array}$ & 30 & 1,1 & 90,7 \\
\hline 9. & $\begin{array}{l}\text { Dimensi part tidak sesuai pada proses } \\
\text { shrinking }\end{array}$ & 30 & 1,1 & 91,8 \\
\hline 10. & $\begin{array}{l}\text { Potongan circum gutter tidak sesuai dan } \\
\text { tidak rata pada proses expanding }\end{array}$ & 30 & 1,1 & 92,9 \\
\hline 11. & $\begin{array}{l}\text { Dimensi part tidak sesuai dan adanya tajam } \\
\text { pada proses vent/hole }\end{array}$ & 20 & 0,8 & 93,7 \\
\hline 12. & Part masih ada tajam pada proses coining & 20 & 0,8 & 94,5 \\
\hline 13. & $\begin{array}{l}\text { Diameter dan radius part tidak sesuai pada } \\
\text { proses chamfer } 2\end{array}$ & 20 & 0,8 & 95,3 \\
\hline 14. & $\begin{array}{l}\text { Dimensi part tidak sesuai pada proses } \\
\text { rerolling }\end{array}$ & 20 & 0,8 & 96,1 \\
\hline 15. & $\begin{array}{l}\text { Dimensi part, tipe, lot no tidak sesuai pada } \\
\text { proses lever } / \mathrm{h} \# 1 \& \text { marking }\end{array}$ & 20 & 0,8 & 96,9 \\
\hline 16. & $\begin{array}{l}\text { Dimensi lever hole } 2 \text { tidak sesuai pada } \\
\text { proses lever } / \mathrm{h} \# 2\end{array}$ & 20 & 0,8 & 97,7 \\
\hline 17. & $\begin{array}{l}\text { Dimensi part tidak sesuai dan adanya tajam } \\
\text { pada proses valve/hole }\end{array}$ & 15 & 0,6 & 98,3 \\
\hline 18. & $\begin{array}{l}\text { Dimensi part tidak sesuai pada proses } \\
\text { notching }\end{array}$ & 12 & 0,5 & 98,8 \\
\hline 19. & $\begin{array}{l}\text { Terjadi retak pada part pada } \\
\text { trimming }\end{array}$ & 10 & 0,4 & 99,2 \\
\hline 20. & $\begin{array}{l}\text { Dimensi part tidak sesuai pada proses } \\
\text { drawing }\end{array}$ & 10 & 0,4 & 99,6 \\
\hline 21. & $\begin{array}{l}\text { Terjadi retak pada part pada proses side cut } \\
\& \text { round }\end{array}$ & 5 & 0,2 & 99,8 \\
\hline 22. & $\begin{array}{l}\text { Lubang valve rim tidak sesuai dan tidak } \\
\text { lurus dengan lubang valve disc pada proses } \\
\text { press }\end{array}$ & 2 & 0,1 & 99,9 \\
\hline 23. & $\begin{array}{l}\text { Lebar hasil pengelasan tidak sesuai dan } \\
\text { terjadi blow hole serta pin hole pada proses } \\
\text { full welding }\end{array}$ & 2 & 0,1 & 100 \\
\hline & Total & 2629 & 100 & \\
\hline
\end{tabular}




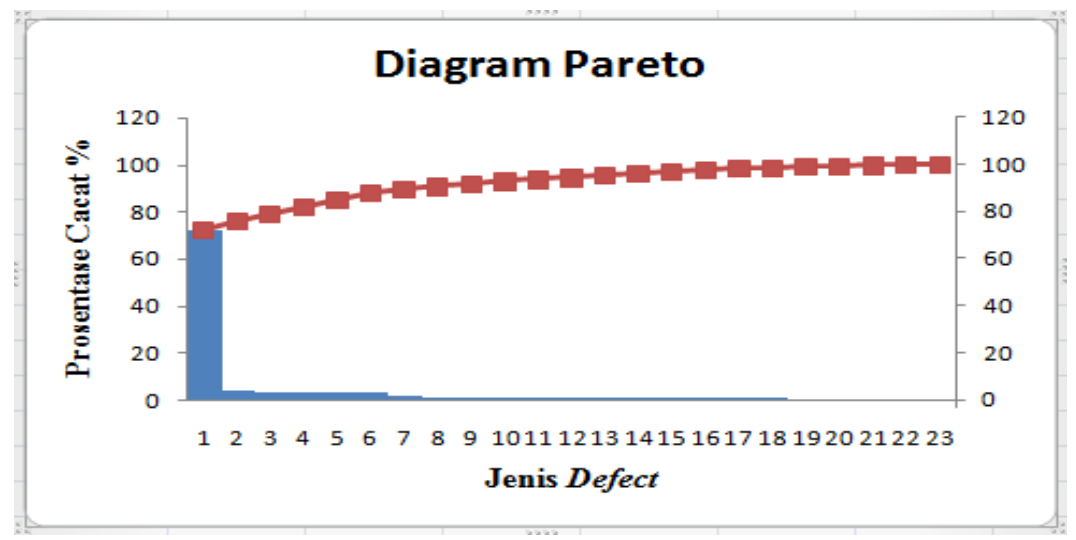

Gambar 1. Diagram pareto jumlah jenis defect proses produksi velg tipe 6.00h164 x 16

Berdasarkan diagram pareto didapatkan bahwa prioritas perbaikan untuk waste defect proses produksi velg tipe $6.00 \mathrm{H} 164 \times 16$ dimensi part tidak sesuai pada proses expanding .

\section{Tahap Improve}

Pada tahap Improve hal yang dilakukan adalah menentukan urutan prioritas perbaikan berdasarkan nilai RPN (risk priority number) yang menjadi penyebab terjadinya defect pada produksi velg tipe $6.00 \mathrm{H} 164 \times 16$ dan menentukan usulan perbaikan yang menjadi penyebab terjadinya waste.

Tabel 5. Usulan perbaikan untuk proses produksi velg tipe $6.00 \mathrm{~h} 164 \mathrm{x} 16$

\begin{tabular}{|l|l|c|c|c|}
\hline No. & \multicolumn{1}{|c|}{$\begin{array}{l}\text { Potensial } \\
\text { Problem }\end{array}$} & \multicolumn{1}{|c|}{ Penyebab } & RPN & Usulan Tindakan Perbaikan \\
\hline 1. & $\begin{array}{l}\text { Dimensi part } \\
\text { tidak sesuai } \\
\text { pada proses } \\
\text { expanding }\end{array}$ & Part terjadi pecah & 512 & $-\begin{array}{l}\text { Perubahan standar dalam } \\
\text { pemilihan bahan baku }\end{array}$ \\
& & $\begin{array}{l}\text { Pengujian ketahanan } \\
\text { terhadap bahan baku } \\
\text { Pengecekan bahan baku } \\
\text { sebelum digunakan }\end{array}$ \\
\hline
\end{tabular}

\section{Tahap Control}

Pada tahap ini akan dilakukan review terhadap hasil improve dan pengusulan rekomendasi perbaikan. Dari hasil review, dapat disimpulkan bahwa usulan perbaikan dapat diimplementasikan untuk mereduksi waste kritis. Oleh karena itu pengusulan rekomendasi ini untuk preventive action agar kejadian yang sama tidak terulang lagi. Berikut adalah beberapa rekomendasi usulan yang dapat diimplementasikan dan dapat dijadikan sebagai acuan standar kerja: pemeriksaan kembali part yang diletakan pada mesin sebelum proses berjalan, pemeriksaan mesin produksi sebelum mesin tersebut digunakan, pergantian alat - alat produksi yang sudah aus, pergantian part baru, perawatan mesin-mesin produksi secara berkala min satu bulan sekali, pemberian training tentang cara penerapan metode line balancing pada bagian produksi.

\section{KESIMPULAN}

Jenis cacat dan pemborosan proses yang terjadi didalam proses produksi velg tipe $6.00 \mathrm{H} 164$ x 16 yaitu didalam proses produksi velg tipe $6.00 \mathrm{H} 164 \times 16$ ini jenis cacat dengan jumlah defect tertinggi adalah dimensi part tidak sesuai pada proses expanding didalam proses produksi rim dengan jumlah defect 1900 unit/lima bulan pengamatan. Jenis pemborosan proses (waste waiting) yang terjadi didalam proses produksi velg tipe $6.00 \mathrm{H} 164 \times 16$ adalah salah satunya terjadi bottleneck pada proses drawing didalam proses disc. Jenis pemborosan proses (waste 
motion) yang terjadi didalam proses produksi velg tipe $6.00 \mathrm{H} 164 \times 16$ adalah operator meraih produk dari proses sebelumnya ke proses yang ditangani operator tersebut, dan menumpuk produk untuk memisahkan antara defect dengan yang baik. Jenis pemborosan proses (waste transportation) yang terjadi didalam proses produksi velg tipe $6.00 \mathrm{H} 164$ x 16 adalah jarak antara proses assy dengan proses paint sejauh $100 \mathrm{~m}$. Dimana jarak tersebut dapat memakan waktu selama $95 \mathrm{~s}$ sehingga tidak efisien. Dan rekomendasi usulan perbaikan tingkat defect tertinggi dan pemborosan proses terjadi, guna diimplementasikan dan dapat sebagai acuan standart kerja yaitu pergantian part baru,pemberian training tentang cara penerapan metode line balancing pada bagian produksi, dan perubahan layout dengan memperhitungkan jarak dan waktu agar lebih efisien.

\section{DAFTAR PUSTAKA}

[1]. Lindsay, Evans, 2005. “An Introducing to Six Sigma \& Process Improvement”: Pengantar Six Sigma, Jakarta: Salemba Empat

[2]. Arlianto, Jerry Agus, Meiriani Salim, dan Anantasari, 2009. Perbaikan Kualitas Proses Produksi Dengan Pendekatan Lean - Sigma Pada Divisi Produksi II, PT. Ilufak Plaskaging, Sidoarjo. skripsi. Jurusan Teknik Industri, Universitas Surabaya.

[3]. Nurwidiana, dan Moehamad Aman, 2009. Evaluasi Hasil Implementasi Lean Six Sigma Berdasarkan Nilai COPQ Menggunakan Pendekatan FMEA. skripsi Teknik Industri. Jurusan Teknik Industri, Universitas Muhammadiyah Magelang.

[4]. Pusporini, Pregiwati dan Deny Andesta, 2009. Integrasi Model Lean Sigma Untuk Peningkatan Kualitas Produk. Gresik. Skripsi Teknik Industri. Jurusan Teknik Indutstri, Universitas Muhammadiyah Gresik.

[5]. Pande, Peter S., Neuman, Robert P., Cavanagh, Roland R. 2002. The Six Sigma Way (Bagaimana GE, Motorola, dan Perusahaan Terkenal Lainnya Mengasah Kinerja Mereka), Andi, Yogyakarta

[6]. Yamit, Zulian, 2001. Manajemen Kualitas Produk dan Jasa, Ekonosia, Yogyakarta

[7]. Gasperz, Vincent, 2007. Lean Six Sigma For Manufacturing and Service Industries, PT. Gramedia Pustaka Utama, Jakarta.

[8]. AAIG (Automotive Industri Action Group) 
- Halaman ini sengaja dikosongkan - 